\title{
The relationship between the Type A behavior pattern and process versus impact achievement motivation
}

\author{
STEPHEN F. DAVIS and CATHY A. GROVER \\ Emporia State University, Emporia, Kansas \\ CYRIL J. SADOWSKI \\ Auburn University at Montgomery, Montgomery, Alabama \\ JAMES L. TRAMILL \\ Wichita State University, Wichita, Kansas \\ and \\ P. JEANNIE KLEINHAMMER-TRAMILL \\ Associated Colleges of Central Kansas, McPherson, Kansas
}

\begin{abstract}
Based upon Friedman and Rosenman's (1977) characterization of the Type A individual, it was predicted that Type As would show higher levels of impact (as opposed to process) achievement motivation than would Type Bs. The modified Jenkins Activity Survey and the Success Behaviors Questionnaire were administered to 352 undergraduate college students to measure Type A/B characteristics and process versus impact achievement orientation, respectively. The results were generally supportive of this prediction.
\end{abstract}

In their seminal article, Friedman and Rosenman (1977) characterized Type A individuals as possessing (1) a sense of time urgency, or "hurry sickness"; (2) competitive achievement, or an intense quest for quantitative accumulation; (3) high levels of aggressiveness and free-floating hostility; and (4) insecurity of status. An extensive amount of research supports this four-fold characterization. For example, the findings that Type A individuals display greater impairment than Type Bs on a task requiring a delay (Glass, Snyder, \& Hollis, 1974) and continually underestimate the lapse of 1 min (Burnam, Pennebaker, \& Glass, 1975) support the conclusion concerning "hurry sickness." Several studies have reported elements of striving for competitive achievement. Carver, Coleman, and Glass (1976), for example, reported that Type As repeatedly suppressed fatigue and performed closer to their endurance levels than did Type Bs in order to continue a challenging but tiring task. In support of differential aggressiveness, Carver and Glass (1978) found that Type A participants were more aggressive than Type B participants when provoked by an annoying confederate or a frustrating task. The insecurity of status characteristic leads to the prediction that Type As should be more highly controlled by external forces, such as significant others

Address correspondence to S. F. Davis, Department of Psychology, Emporia State University, Emporia, KS 66801-5087. and/or authority figures, than are Type Bs. Davis, Fouty, Tramill, and Sadowski (1985) reported data supportive of this prediction.

Certainly, the competitive achievement characteristic suggests that the Type A individual should score quite high on measures of achievement motivation. A variant of this theme formed the basis for the present study. Veroff (1977) correctly indicated that "we have come a long way in the scientific study of achievement motivation since McClelland and his coworkers (1953) introduced the systematic study of achievement motivation through projective testing"' (p. 283). Succinctly, Veroff suggested that it is inappropriate to characterize achievement motivation as a unidimensional construct. He indicated that one might choose to achieve because of the impact produced by the accomplishment. On the other hand, for some individuals, enjoyment of the process of achieving may be the root of this type of motivation.

As the Type A individual characteristically displays insecurity of status, he/she should be concerned with the impact of an achievement rather than with the process of achieving. On the other hand, there appears to be no clearcut prediction regarding the prevalence of process versus impact orientations for Type B individuals. As Type B is simply defined as the relative absence of Type A characteristics, it might be argued that neither orientation would dominate. 


\section{METHOD}

\section{Subjects}

A total of 352 undergraduate college students (106 males, 246 females) volunteered to participate in the study. The subjects attended a mediumsized regional midwestern university.

\section{Test Instruments}

The modified Jenkins Activity Survey for Health Predictions (JAS; Krantz, Glass, \& Snyder, 1974) was used to measure Type A/B characteristics. The JAS is a 21 -item multiple-choice questionnaire with a normative mean of 8 and a standard deviation of 4 .

The Success Behaviors Questionnaire (SBQ) is a measure of the process and impact orientations described by Veroff (1977). Each orientation is represented by seven traits found to be exemplars of the orientations (Sadowski \& Long-Hall, 1985). The traits are rated on a 5-point scale denoting the extent to which a respondent believes it is important to possess the trait to be successful. Scores for each orientation can range from 7 to 35 . For a sample of 180 undergraduates, alpha coefficients for the process and impact scales were .71 and .79 , respectively (Sadowski \& Long-Hall, 1985). Test-retest correlations over a week were $r(72)=.73, p<.001$, for the process scale and $r(72)=.74$, $p<.001$, for the impact scale (Sadowski, personal communication, February 1986).

\section{Procedure}

The investigators combined the testing instruments into a booklet which students self-administered during a regular class session. Other than instructions pertaining to the distribution and collection of the booklets and answer sheets, the investigators provided no explicit instructions.

\section{RESULTS}

Based upon the normative data reported by Krantz et al. (1974), the investigators designated individuals with JAS scores of 9-12 (+1SD) as $\mathrm{A}-$, that is, having some Type A characteristics; those with scores above 12 $(+2 S D)$ as $\mathrm{A}+$, that is, having pronounced Type $\mathrm{A}$ characteristics; those with scores of 5-7 (-1SD) as B-, that is, having some Type B characteristics; and those with scores of 0-4 (-2 SD) as $\mathrm{B}+$, that is, having pronounced Type B characteristics. Mean process and impact scores from the SBQ, arranged by gender over the four personality types, are shown in Table 1 .

A split-plot factorial, unweighted-means analysis of variance (Kirk, 1968) was performed on the process/impact data. Personality type $(\mathrm{A}+, \mathrm{A}-, \mathrm{B}-$, and $\mathrm{B}+$ ) and gender (male vs. female) served as betweensubjects factors; orientation on the SBQ (process vs. impact) served as the within-subjects factor. The results in-

Table 1

Mean Process and Impact Scores on the Success Behaviors Questionnaire for Males and Females as a Function of Personality Type

\begin{tabular}{ccccc}
\hline & \multicolumn{4}{c}{ Personality Type } \\
\cline { 2 - 5 } Gender & $\mathrm{B}+$ & $\mathrm{B}-$ & $\mathrm{A}-$ & $\mathrm{A}+$ \\
\hline Male & $(n=9)$ & $(n=39)$ & $(n=29)$ & $(n=29)$ \\
Process & 21.67 & 23.26 & 23.79 & 25.03 \\
Impact & 23.00 & 23.21 & 23.41 & 31.69 \\
Female & $(n=27)$ & $(n=87)$ & $(n=80)$ & $(n=52)$ \\
Process & 22.44 & 23.49 & 23.75 & 24.83 \\
Impact & 21.37 & 21.48 & 22.16 & 30.33 \\
\hline
\end{tabular}

dicated that the main effect of personality type $[F(3,44)=$ $4.53, p<.01]$ and the interaction of personality type $\times$ orientation on the SBQ $[F(3,44)=4.06, p<.05]$ were significant. Also worthy of note was the finding that the gender $\times$ orientation on the SBQ interaction approached significance $[F(1,244)=3.83, p>.05]$. The NewmanKeuls procedure was used to determine specific effects associated with the significant omnibus $F$ ratios. These tests revealed that, generally speaking, the Type A+ subjects had significantly $(p<.01)$ higher scores than did the three other personality types, which did not differ significantly among themselves. Additional tests indicated that the Type A+ subjects' impact scores were significantly higher $(p<.01)$ than the scores in all other conditions.

\section{DISCUSSION}

As the characteristics delineated by Friedman and Rosenman (1977) would lead one to anticipate, the most pronounced Type A individuals in the present study scored significantly higher in achievement motivation, whether it be process or impact, than did the other personality types. Also, as predicted, the Type A subjects, regardless of gender, were more concerned with the impact of their achievements than with the mere process of achieving. This was clearly reflected in the significantly higher impact scores of the Type A+ subjects.

These results prompt several observations. First, the elevated impact scores shown by the Type A+ subjects suggest that they should have a higher level of external orientation than their Type B counterparts. Davis et al. (1985) reported data supportive of this prediction.

More speculatively, it might be proposed that the stress placed upon the impact of achievements may lead to a need to maintain an "image of success." Such constant pressures may well be one of the causes of burnout. Clearly, it would be predicted that Type A+ individuals would be more prone to burnout than the other personality types we have considered.

On the other hand, Rhodewalt and Agustsdottir (1984) suggested that the relationship between Type $\mathrm{A}$ behavior and such negatives as burnout may not be as clear-cut or simplistic as the above analysis may suggest. Similarly, Matthews (1982) indicated that the multidimensional nature of Type A behavior has not been fully appreciated and/or understood. Thus, other, possibly more prosocial, interpretations of the present data are possible. For example, Type As may value the impact of an achievement because of a desire to effect positive social changes. Additional research into the complexities of this behavior pattern is clearly indicated.

\section{REFERENCES}

Burnam, M. A., Pennebaker, J. W., \& Glass, D. C. (1975). Time consciousness, achievement striving, and the Type A coronary-prone behavior pattern. Journal of Abnormal Psychology, 84, 76-79.

Carver, C. S., Coleman, A. E., \& Glass, D. C. (1976). The coronaryprone behavior pattern and the suppression of fatigue on a treadmill test. Journal of Personality \& Social Psychology, 33, 460-466.

Carver, C. S., \& Glass, D. C. (1978). Coronary-prone behavior pattern and interpersonal aggression. Journal of Personality \& Social Psychology, 36, 361-366.

Davis, S. F., Fouty, H. E., Tramill, J. L., \& SADowsKi, C. J. (1985, April). The relationship between the Type A and Type B behavior patterns and locus of control. Paper presented at the annual meeting of the Southern Society for Philosophy and Psychology, New Orleans, LA.

Friedman, M., \& Rosenman, R. H. (1977). The key cause: Type A behavior pattern. In A. Monat \& R. S. Lazrus (Eds.), Stress and coping (pp. 203-212). New York: Columbia University Press. 
Glass, D. C., SNyder, M. L., \& Hollis, J. F. (1974). Time urgency and the Type A coronary-prone behavior pattern. Journal of Applied Social Psychology, 4, 125-140.

KIRK, R. E. (1968). Experimental design: Procedures for the behavioral sciences. Belmont, CA: Brooks/Cole.

Krantz, D. S., Glass, D. C., \& SNyder, M. L. (1974). Helplessness, stress level, and the coronary-prone behavior pattern. Journal of Experimental Social Psychology, 10, 284-300.

Matthews, K. A. (1982). Psychological perspectives on the Type A behavior pattern. Psychological Bulletin, 91, 292-323.

McClelland, D. C., Atkinson, J. W., Clark, R. A., \& Lowell, E. L. (1953). The achievement motive. New York: Appleton-CenturyCrofts.
Rhodewalt, F., \& AGUSTSDotTir, S. (1984). On the relationship of hardiness to the Type A behavior pattern: Perception of life events versus coping with life events. Journal of Research in Personality, 18, 212-223.

Sadowski, C. J., \& Long-Hall, C. K. (1985). Achievement orientations as prototypes. Psychological Reports, 57, 1087-1090.

VEROFF, J. (1977). Process vs. impact in men's and women's achievement motivation. Psychology of Women Quarterly, 1, 283-293.

(Manuscript received for publication July 8, 1986.) 